\section{Dr. Wegner, et al, reply}

To the Editor:

We thank the author for sparking a discussion about differences and similarities of radiographic pathologies between rheumatoid arthritis (RA) and spondyloarthropathies ${ }^{1}$. Indeed, it can sometimes be a challenge to discriminate at an early stage of the disease, especially when having only 1 diagnostic tool at hand, e.g., radiographic studies. However, the clinical description that we have included alongside the radiologic image ${ }^{2}$ excludes a differential diagnosis such as psoriatic arthritis. And clearly, one should "bear" in mind the most common cause for changes of the distal interphalangeal joints: Heberden nodes. We have to deny that our radiographs of hands with RA are identical to those presented by Rothschild, because the most distinctive difference between them is the fusion of the bases of the metacarpal bones in the bear's paw.

FRANZ WEGNER, MD, University Hospital Schleswig Holstein, Campus Lübeck, Department of Radiology and Nuclear Medicine, Lübeck, and

University of Giessen, Department of Rheumatology and Clinical
Immunology, Kerckhoff Clinic, Bad Nauheim, Germany;

ULF MÜLLER-LADNER, MD, University of Giessen, Department of

Rheumatology and Clinical Immunology, Kerckhoff Clinic; FLORIAN

M.P. MEIER, MD, University of Giessen, Department of Rheumatology and Clinical Immunology, Kerckhoff Clinic. Address correspondence to

Dr. U. Müller-Ladner, University of Giessen, Department of

Rheumatology and Clinical Immunology, Benekestrasse 2-8,

Kerckhoff Clinic, Bad Nauheim 61231, Germany.

E-mail: u.mueller-ladner@kerckhoff-klinik.de

\section{REFERENCES}

1. Rothschild BM. Reconsideration of disappearing and fusing wrists. J Rheumatol 2018;45:875.

2. Wegner F, Müller-Ladner U, Meier FM. Missing wrists in a patient with rheumatoid arthritis: a matter of compliance. J Rheumatol 2017;44:655.

J Rheumatol 2018;45:6 doi:10.3899/jrheum.171439 